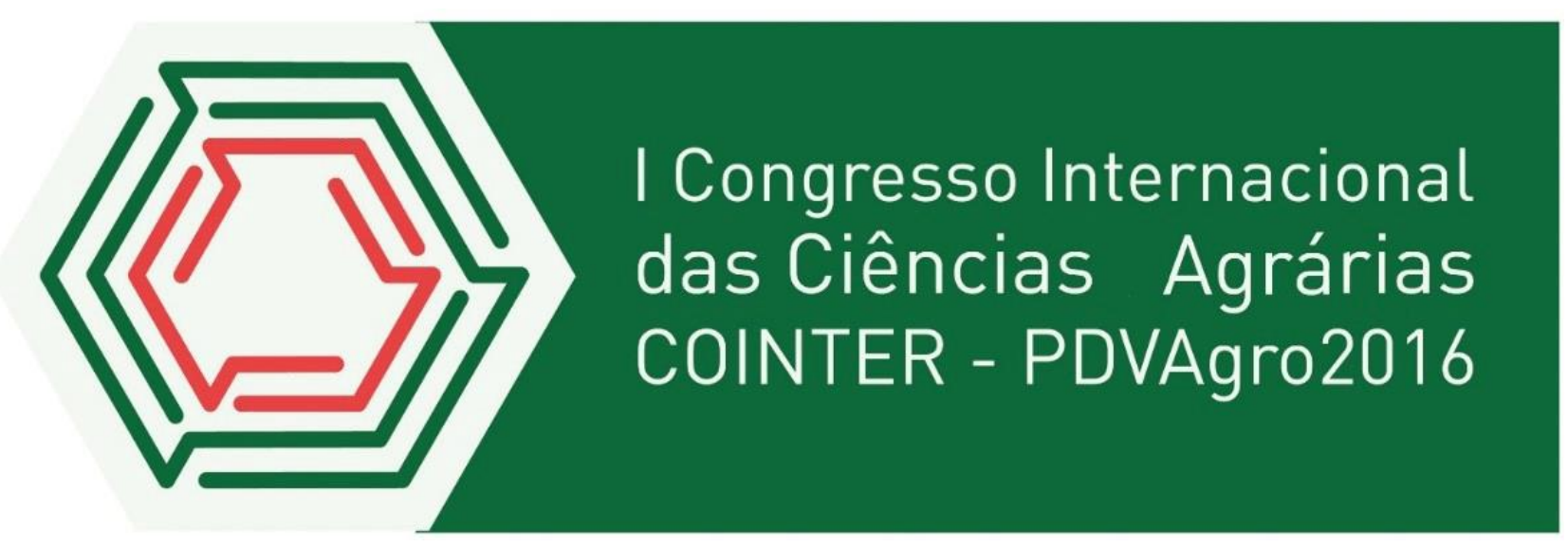

\title{
ANÁLISE EXPLORATÓRIA DO USO DE ÁGUAS SUBTERRÂNEAS EM MUNICÍPIOS DA ZONA DA MATA DE PERNAMBUCO
}

\author{
Apresentação: Comunicação Oral
}

Fabrício Ângelo Gabriel ${ }^{1}$; Edja Lillian Pacheco da Luz ${ }^{2}$

\begin{abstract}
Resumo
Diante de seu caráter de essencialidade à vida, a água é um recurso natural utilizado como insumo básico para a maioria das atividades realizadas pelo homem seja para sua subsistência, para o uso industrial ou na realização de atividades econômicas rurais. Neste contexto, as águas subterrâneas entram como uma fonte alternativa de abastecimento da população na maioria dos municípios do Brasil, inclusive no Estado de Pernambuco, afim de atender as necessidades em tempos de longa estiagem. Diante do exposto, o presente trabalho teve por objetivo identificar a finalidade e a situação dos poços tubulares em alguns municípios da Zona da Mata de Pernambuco. Os dados foram obtidos por meio do Sistema de Informação de Águas Subterrâneas. Foram identificados 696 poços distribuídos em 11 municípios. Destes, 34,5\% são de uso doméstico, 5,5\% para abastecimento múltiplo e 3,3\% para abastecimento industrial, sendo que em sua maioria estão bombeando (23,5\%), seguido por poços equipados (13\%) e não instalados (5\%). Em relação a profundidade útil, a maior parte dos poços dentre aqueles com dados identificados, possuíam profundidade de baixa a média. Desta forma, com os resultados obtidos, verifica-se que é necessário a realização de fiscalização e monitoramento permanentes e efetivos afim de proteger a qualidade da água subterrânea e consequentemente a saúde da população que faz uso desta tornando-a de fundamental importância não só para o meio ambiente natural como também para o social. Da mesma forma, a população deve agir como verdadeira protagonista no gerenciamento das atividades que possam vir a comprometer este recurso, haja vista a complexidade na manutenção e preservação destes mananciais que necessitam de muito tempo, quando poluídas, para sua renovação.
\end{abstract}

Palavras-Chave: Meio ambiente, agricultura, recurso hídrico, SIAGAS.

\section{Introdução}

A região nordeste do Brasil apesar de rica em recursos hídricos sofre com longos períodos de estiagem, que acabam interferindo nos níveis das barragens da rede de abastecimento de água da população de Pernambuco. Outro problema agravante enfrentado é a distância dos pontos de

\footnotetext{
1 Mestrando em Engenharia Ambiental, Universidade Federal Rural de Pernambuco, fabricio.gabriel@outlook.com

${ }^{2}$ Mestranda em Engenharia Ambiental, Universidade Federal Rural de Pernambuco, lillian2800@hotmail.com
} 
captação e tratamento e as localidades mais afastadas dos centros urbanos fazendo com que a população e até mesmo as indústrias façam uso das águas subterrâneas como alternativa ou mesmo como única fonte de abastecimento para atender a sua demanda de água.

Sabe-se que os cursos hídricos subterrâneos possuem papel essencial na composição das nascentes, riachos e rios que formam as bacias hidrográficas. Logo para que seja mantida a qualidade e equilíbrio das reservas reguladoras do aquífero é necessário que haja um manejo adequado do volume retirado e sejam tomadas medidas de conservação dos poços para evitar a sua superexploração, contaminação e consequentemente exaustão do aquífero.

Apesar das águas subterrâneas estarem mais protegidas dos agentes contaminantes do que as superficiais, a grande expansão das atividades antrópicas, nas áreas urbanas e rurais, tem provocado cada vez mais a poluição deste recurso.

Observa-se ainda que, os próprios poços tubulares, cisternas e cacimbões, quando construídos sem o devido acompanhamento técnico de profissional capacitado e fora das exigências das normas técnicas, constituem-se em possível fonte de contaminação dos aquíferos, comprometendo a sua qualidade, particularmente devido à contaminação por agentes biológicos, associados à falta de saneamento básico (LEMOS et al., 2002).

Diante dessa problemática essa pesquisa busca traçar um diagnóstico do uso das águas subterrâneas da Zona da Mata afim de conhecer quais demandas estão sendo atendidas através da exploração das águas subterrâneas em municípios dessa região, se para as necessidades de uso doméstico da população, fins industriais, irrigação de lavouras, ou outros fins.

Este diagnóstico abrange também a situação atual em que estão sujeitos os poços pesquisados, se estes encontram-se em bombeamento regular, obstruído, parado, abandonado ou em estado precário de conservação. Buscou-se ainda verificar os diferentes níveis de profundidades nos poços estudados uma vez que estes dados são necessários em estudos futuros que envolvam o monitoramento dos níveis de rebaixamento do volume de água dos aquíferos da Zona da Mata pernambucana.

\section{Fundamentação Teórica}

A região Nordeste é caracterizada pelas chuvas irregulares sujeita a períodos prolongados de estiagem, provocando entrave no desenvolvimento socioeconômico e, inclusive, à subsistência da população local (CPRM, 2011). Costa et al. (2006) explicita que a região semiárida do nordeste 
brasileiro, além da irregularidade de chuvas, a seca está aliada a elevada taxa de evapotranspiração. No entanto, esses fatores influenciam e desfavorecem a produção agrícola convencionais em sequeiro, mas ao mesmo tempo existem nesta região reservas subterrâneas que poderiam ser uma saída das longas estiagens da região (SANTOS et al., 2010).

O Estado de Pernambuco se localiza na região Nordeste e possui limites com os Estados da Paraíba e Ceará, ao Norte, Oceano Atlântico ao Leste, ao Oeste e Sul com os Estados do Piauí e Bahia, e o Estado de Alagoas ao Sul (BRASIL, 2012). A Zona da Mata de Pernambuco é subdividida em Zona da Mata Norte e Zona da Mata Sul, apresenta índices pluviométricos anuais que podem variar de 1.000 milímetros em regiões mais secas, a valores superiores a 2.500 milímetros em regiões que ficam próximas a faixa litorânea (COSTA; CIRILO, 2010)

Silva et al. (1999) alega que no Estado de Pernambuco a necessidade hídrica é saciada por mananciais superficiais para diversas finalidades, visto que boa parte de seu território fica localizado sobre áreas de baixa vocação hidrogeológica. $\mathrm{O}$ autor supracitado ainda ressalta que as condições climatológicas provocaram a escassez da água superficial nos últimos anos e, como alternativa, tiveram que explorar áreas que eram propícias a captação de água subterrânea, o que vem sendo realizada de forma desordenada.

De modo geral, a ocorrência de água subterrânea vai variar conforme as características da região e a atuação de alguns fatores.

As condições de ocorrência das águas subterrâneas numa região são muito variadas na medida em que dependem da interação de fatores climáticos e aspectos geológicos. A análise integrada destes, associada aos aspectos de relevo, solo e vegetação, constitui a base da caracterização das províncias hidrogeológicas, o que auxilia na melhor locação de um poço (XAVIER, 2014).

Segundo Costa (2002), conforme citado por Costa et al. (2006), o recurso hídrico subterrâneo se encontra preenchendo fendas e fraturas das rochas formando um aquífero fissural e, apesar de ser caracterizado com baixo potencial hidrogeológico e alta concentração de sal, é utilizado amplamente pela população rural e na pecuária.

Silva Júnior (1999) alega que no Nordeste existe milhares de poços que são utilizados para irrigação, o que se destaca como fundamental insumo na cadeia produtiva; contudo, a qualidade da água pode variar no tempo e no espaço, sendo que o uso de má qualidade pode acarretar sérios prejuízos com reflexos socioeconômicos. Neste contexto, a irrigação realizada com água que possui concentração alta de sais pode ser prejudicial à cultura e deve, no entanto, ser realizada com práticas que favoreçam a não acumulação excessiva de sais no solo, minimizando o estresse decorrente da 
elevada concentração de sais (GARCIA et al., 2008). Acrescenta-se que a utilização da água subterrânea com alto índice de salinidade para fins de irrigação fica condicionada ao seu manejo e a culturas que possui tolerância (MEDEIROS et al., 2003).

Poucos são os estudos voltados para as águas subterrâneas no Brasil, além de carecer de bases de dados correto e possuindo grande abrangência, sendo que se pode destacar a base de dados SIAGAS da Companhia de Pesquisas de Recursos Minerais (CPRM) (LÖBLER et al, 2014).

\section{Metodologia}

O estudo foi realizado na Zona da Mata do Estado de Pernambuco, perfazendo um total de 11 municípios analisados. Os dados foram obtidos nos arquivos da Companhia de Pesquisa de Recursos Minerais (CPRM) com base no Sistema de Informações de Águas Subterrâneas (SIAGAS). Para tanto, foram selecionados os municípios com maior número de poços registrados na região da Zona da Mata de Pernambuco, abrangendo tanto o Norte quanto o Sul da respectiva região.

\begin{tabular}{|c|c|c|}
\hline Município & Região & N $^{\mathbf{o}}$ de Poços \\
\hline Vitória de Santo Antão & Zona da Mata Sul & 149 \\
\hline Itambé & Zona da Mata Norte & 42 \\
\hline Glória do Goitá & Zona da Mata Norte & 43 \\
\hline Gameleira & Zona da Mata Sul & 43 \\
\hline Quipapá & Zona da Mata Sul & 41 \\
\hline Carpina & Zona da Mata Norte & 60 \\
\hline Goiana & Zona da Mata Norte & 104 \\
\hline Nazaré da Mata & Zona da Mata Norte & 54 \\
\hline Paudalho & Zona da Mata Norte & 54 \\
\hline Água Preta & Zona da Mata Sul & 50 \\
\hline Palmares & Zona da Mata Sul & 56 \\
\hline
\end{tabular}

\section{Resultados e Discussão}

Perfazendo um total de 696 poços, distribuídos nos 11 municípios estudados, verificou-se que a grande maioria dos poços $(34,5 \%)$, daqueles que possuíam identificação de uso, tinham suas águas utilizadas para abastecimento doméstico, seguido por abastecimento múltiplo com 5,5\% e 
industrial com 3,3\% e abastecimento urbano com 3,2\% (Fig.1). A utilização da água subterrânea para irrigação e abastecimento animal embora em menor representação quando comparada aos demais fins ainda se faz presente na Zona da Mata de Pernambuco, representando um total de $2 \%$ e $1 \%$, respectivamente, dos poços registrados das cidades tratadas.

Figura 1. Utilização das águas subterrâneas em municípios da Zona da Mata pernambucana.

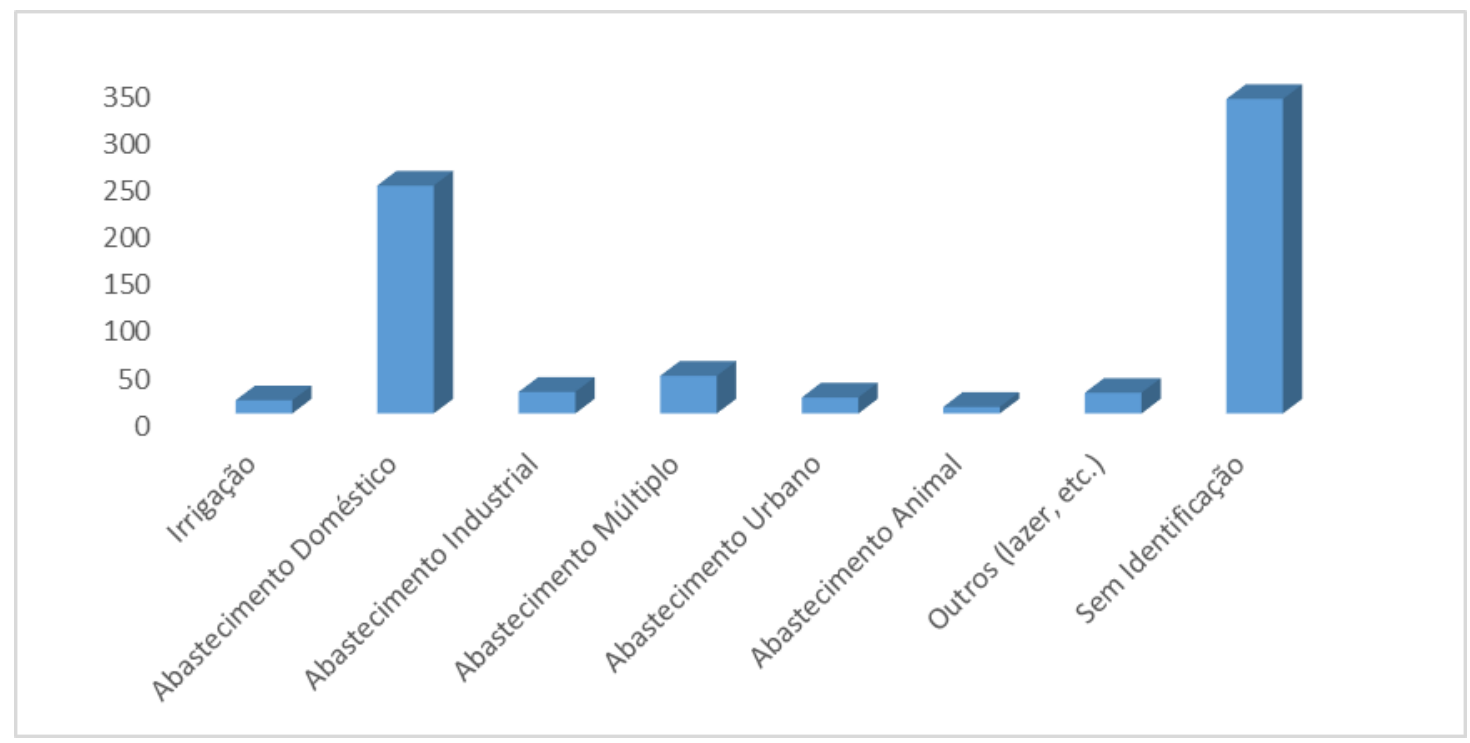

Quanto ao estado desses poços, entre que tinha sua situação descrita, a maioria $(23,5 \%)$ se encontra bombeando água regularmente, $13 \%$ foram descritos como equipados, $5 \%$ ainda não estavam instalados, $4,6 \%$ estavam sem funcionamento, $3 \%$ encontravam-se obstruídos, $2,8 \%$ foram abandonados e menos de $2 \%$ estava secos ou em estado precário de conservação (Fig. 2). Quanto a profundidade útil, a maior parte dos poços dentre aqueles com dados identificados, possuíam profundidade de baixa a média (Fig. 3).

Figura 2. Situação dos poços estudados em municípios da Zona da Mata pernambucana. 


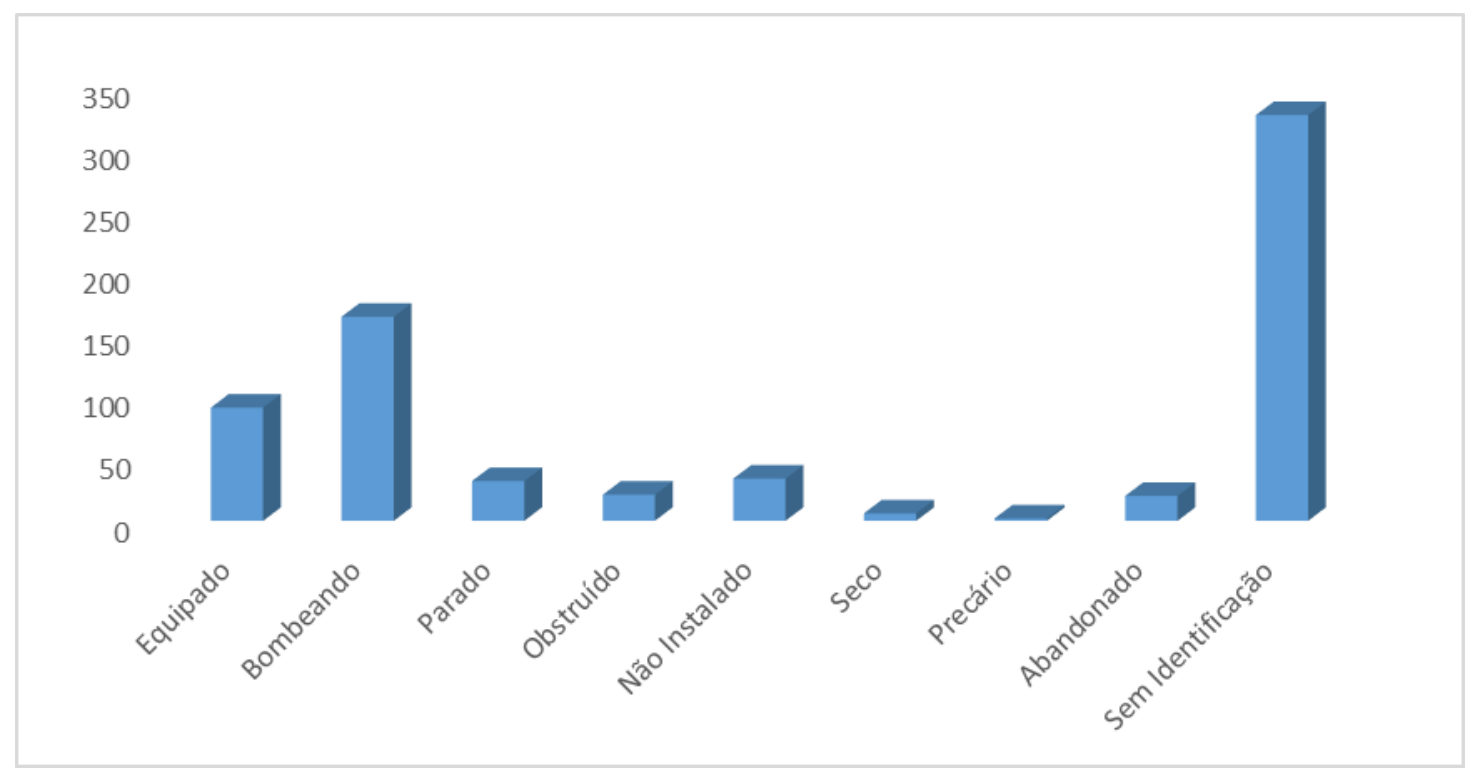

Figura 3. Profundidade em metros dos poços estudados na Zona da Mata pernambucana.

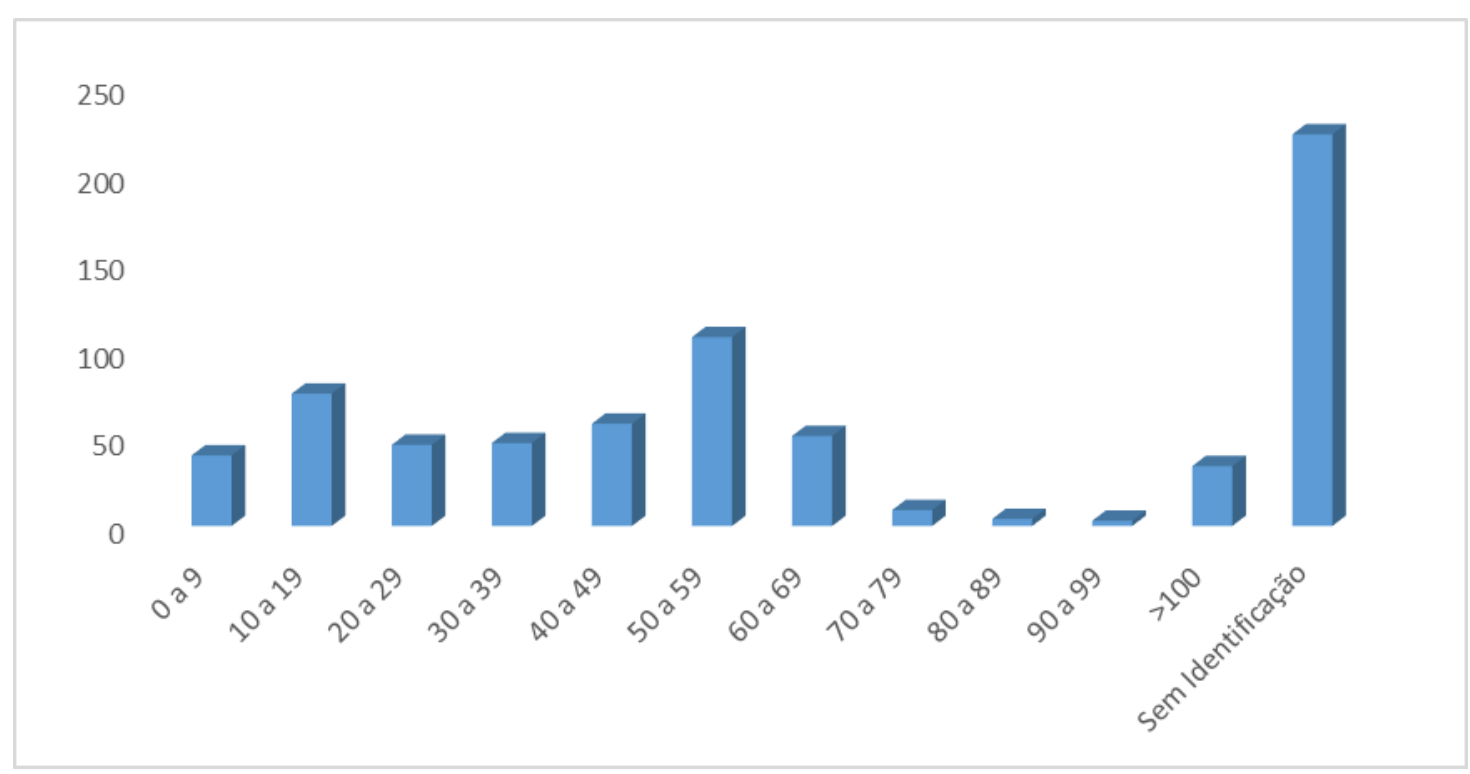

Gabriel (2015) realizando o diagnóstico dos poços na região Semiárida do Estado de Pernambuco, expressa que a maior utilização da água subterrânea é para uso doméstico (27\%), corroborando com o presente trabalho, no entanto, o abastecimento animal obteve 25\%, diferentemente da Zona da Mata com apenas 1\%. De acordo com Silva et al (2008), o crescimento do uso da água subterrânea em municípios pernambucanos, na última década, foi em consequência do comprometimento dos mananciais superficiais pela longa estiagem. Esse fator favoreceu a exploração desordenada dos aquíferos para suprir a necessidade humana em condomínios residenciais e abastecimento comercial e industrial (SILVA et al., 2008).

Garcia et al. (2008) destaca que as concentrações altas de sais advindas da irrigação podem 
interferir diretamente na produtividade e produção das culturas. Logo, o conhecimento da qualidade da água se torna imprescindível quando se é destinado à irrigação, pois é possível preceder com o planejamento da exploração desse recurso e ao correto manejo a ser empregado (ANDRADE JÚNIOR, 2006).

De acordo com o trabalho de Silva (1999) a utilização da água subterrânea para fins de irrigação na Região Metropolitana do Recife, Pernambuco, não é expressiva, visto que sua maior parte é vinculado ao abastecimento residencial.

Xavier (2014) utilizando a base de dados SIAGAS e realizando vistoria presencial destaca que a maioria dos poços que ficaram secos foi devido à falta de estudo prévio para localização mais precisa do poço, sendo uma área com geologia e solo pouco favorável à obtenção de água com qualidade e em quantidade. A autora ainda ressalta que poços ficaram secos também em virtude de estar ao lado de outros poços bombeando.

Por fim, poços abandonados constituem portas de entrada para contaminantes da água subterrânea que, conforme Godoy et al. (2004), a água impurificada de aquíferos passa por atalhos deixados para zonas inferiores.

Para Nascimento et al. (2008), a base de dados SIAGAS tornou-se de grande importância para contribuir na manutenção do cadastro nacional de poços como fonte de recurso hídrico, além de mencionar que é fundamental para o conhecimento hidrogeológico do país, e subvencionar estudos sobre os mais diversos assuntos que envolve a qualidade e situação das águas subterrâneas.

\section{Conclusões}

Podemos concluir que entre os municípios estudados na Zona da Mata Norte e Sul de Pernambuco a utilização da água subterrânea para abastecimento da população, principalmente para fins de uso doméstico é bastante frequente nessa região. Foi grande também o número de poços com múltiplos usos e de uso restrito ao setor industrial. Com menor representação estavam aqueles destinados à irrigação de lavouras e criação de animais.

Durante a coleta dos dados fornecidos pelo SIAGAS foram observados que grande parte dos poços registrados não possuíam informações completas a respeito do uso de suas águas, profundidade útil do poço e estado de conservação e funcionamento dos poços analisados.

Diante do exposto faz-se necessário a realização de futuros trabalhos que envolvam o monitoramento e fiscalização dos poços registrados nos arquivos da Companhia de Pesquisa de Recursos Minerais, que se mostram de vital importância na saúde da população que precisa deste recurso para atender a demanda de água nessas localidades.

Uma vez que se compreenda a importância desse bem imprescindível, é dever da sociedade 
e governo zelar para a manutenção e qualidade das fontes e aquíferos das quais dependem a regulação das águas subterrâneas assim como também a conservação dos próprios poços de captação dessas águas.

\section{Referências}

ANDRADE JÚNIOR, A. S.; SILVA, E. F. F.; BASTOS, E. A.; MELO, F. B.; LEAL, C. M. Uso e qualidade da água subterrânea para irrigação no Semiárido piauiense. Revista Brasileira de Engenharia Agrícola e Ambiental, v. 10, n. 4, p. 873-880, 2006.

BRASIL. Governo do Estado de Pernambuco. Plano Estadual de Saúde 2012-2015. <http:/ / www.saude.pe.gov.br/arquivos/Versao\%20Preliminar\%202012\%20\%202015.pdf> Acesso em: 02 out. 2016.

CPRM. Projeto Cadastro de Fontes de Abastecimento por Água Subterrânea, Estado do Maranhão: Relatório diagnóstico do município de Coelho Neto. Teresina: CPRM - Serviço Geológico do Brasil, 2011.

COSTA, A. M. B.; MELO, J. G.; SILVA, F. M. Aspectos da salinização das águas do aquífero cristalino no Estado do Rio Grande do Norte, Nordeste do Brasil. Águas Subterrâneas, v. 20, n. 1, p. 67-82, 2006.

COSTA, M. R. C.; CIRILO, J. A. Análise do potencial de uso das águas subterrâneas nas Bacias da Região semiárida do Estado de Pernambuco. Anais do XVI Congresso Brasileiro de Águas Subterrâneas, São Luiz, MA, 2010.

GARCIA, G. O.; MARTINS FILHO, S.; REIS, E. F.; MORAES, W. B.; NAZÁRIO, A. A. Alterações químicas de dois solos irrigados com água salina. Rev. Ciên. Agron. Fortaleza, v. 39, n. 1, p. 7-18, 2008.

GODOY, M. C. T. F.; BOIN, M. N.; SANAIOTTI, D. C.; SILVA, J. B. Contaminação das águas subterrâneas por nitrato em Presidente Prudente - SP, Brasil. Rev. Inst. Adolfo Lutz, 63(2):208-14, 2004.

LEMOS, M. M. G.; SILVA, M. F. B.; DIAS, C. L.; BUCCI, E. M.; CASARINI, D. C. P. Qualidade das águas subterrâneas no Estado de São Paulo, em poços tubulares utilizados para o abastecimento público. Anais XII Congresso Brasileiro de Águas Subterrâneas. Florianópolis, 2002.

LÖBLER, C. A.; TERRA, L. G.; SILVA, J. L. S. Dados da CPRM/SIAGAS e Imagens STRM como Base Cartográfica na Elaboração de Mapeamento em Recursos Hídricos Subterrâneos em Escala Municipal: o Caso de Nova Palma, RS. Revista Brasileira de Geografia Física, v.7, n. 3, p. 513-523, 2014. 
MEDEIROS, J. F.; LISBOA, R. A.; OLIVEIRA, M.; SILVA-JÚNIOR, M. J.; ALVES, L. P. Caracterização das águas subterrâneas usadas para irrigação na área produtora de melão da Chapada do Apodi. Revista Brasileira de Engenharia Agrícola e Ambiental, v. 7, n. 3, p. 469-472, 2003.

NASCIMENTO, F. M. F.; CARVALHO, J. E.; PEIXINHO, F. C. Sistema de informações de água subterrânea - SIAGAS: Histórico, desafios e perspectivas. Anais do XV Congresso Brasileiro de Águas Subterrâneas, Natal - RN, 2008.

SANTOS, A. N.; SOARES, T. M.; SILVA, E. F. F.; SILVA, D. J. R.; MONTENEGRO, A. A. A. Cultivo hidropônico de alface com água salobra subterrênea e rejeito de dessalinização em Ibimirim, PE. Revista Brasileira de Engenharia Agrícola e Ambiental, v. 14, n. 9, p. 961-969, 2010.

SILVA-JÚNIOR, L. G. A.; GHEYI, H. R.; MEDEIROS, J. F. Composição química de águas do cristalino do Nordeste brasileiro. Revista Brasileira de Engenharia Agrícola e Ambiental, v. 3, n. 1, p. 11-17, 1999.

SILVA, S. R.; MONTEIRO, A. B.; CABRAL, J. J. S. P.; BORBA, A. L. S.; FREIRE, P. K. C.; COSTA, W. D.; BARBOSA, G. F. A gestão de águas subterrêneas no aquifero Barreiras - Jordão, Jardim Jordão e Ibura - Recife - Pernambuco. Anais do XV Congresso Brasileiro de Águas Subterrâneas, Natal - RN, 2008.

SILVA, S. R.; MONTEIRO, A. B.; FRANÇA, A. E. O gerenciamento das águas subterrâneas no Estado de Pernambuco. Anais do XIII Simpósio Brasileiro de Recursos Hídricos, Belo Horizonte, MG, 1999.

XAVIER, F. F. Considerações a respeito dos poços parados e secos do município de Floresta, Pernambuco, Brasil. Mestrado (Engenharia Civil - Recursos Hídricos), Universidade Federal de 